Revista de la red interuniversitaria de estudios sobre las literaturas rioplatenses contemporáneas en Francia

8 | 2013

Argentina y Uruguay: lecturas del país vecino en la literatura rioplatense contemporánea (siglos XX y XXI)

\title{
Multiterritorialidad imaginada en la última narrativa uruguaya : a propósito de La vista desde el puente de Ramiro Sanchiz
}

Jesús Montoya Juárez

\section{OpenEdition}

\section{Journals}

Edición electrónica

URL: http://journals.openedition.org/lirico/996

DOI: $10.4000 /$ lirico.996

ISSN: 2262-8339

Editor

Réseau interuniversitaire d'étude des littératures contemporaines du Río de la Plata

\section{Referencia electrónica}

Jesús Montoya Juárez, « Multiterritorialidad imaginada en la última narrativa uruguaya : a propósito de La vista desde el puente de Ramiro Sanchiz », Cuadernos LIRICO [En línea], 8 | 2013, Puesto en línea el 01 enero 2013, consultado el 19 abril 2019. URL : http://journals.openedition.org/lirico/996 ; DOI $10.4000 /$ lirico.996

Este documento fue generado automáticamente el 19 abril 2019.

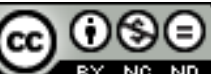

Cuadernos LIRICO está distribuido bajo una Licencia Creative Commons Atribución-NoComercialSinDerivar 4.0 Internacional. 


\title{
Multiterritorialidad imaginada en la última narrativa uruguaya : a propósito de La vista desde el puente de Ramiro Sanchiz
}

\author{
Jesús Montoya Juárez
}

\section{Introducción}

1 El crítico Fernando Aínsa ha señalado cómo en las últimas dos décadas se vuelve un fenómeno insistente la proliferación en América Latina del mismo sentimiento que inspiraba a Flaubert cuando expresaba, en su exilio normando, « No soy más francés que chino $»^{1}$. Piénsese en la Alemania del mexicano Jorge Volpi, los Estados Unidos de Edmundo Paz Soldán, la Rusia del cubano José Manuel Prieto o los jardines de Kensington del argentino Rodrigo Fresán. Uno de los autores que más radicalmente plantean un desafío a la hora de incluirlo en el cajón de sastre de una literatura nacional, Andrés Neuman, argentino afincado en Granada desde su adolescencia, regresa sobre la metáfora del aeropuerto para referir la condición de la literatura actual como una literatura de sujetos «en tránsito $»^{2}$, en la medida en que lo que nos queda en ese punto incierto y fronterizo en "que cabe todo", como es el aeropuerto, es, de nuevo, una "fastidiosa pregunta por la identidad $»^{3}$. Neuman afirma en su texto sentirse vecino de esa pregunta hoy irresoluble, de la idea que Simone Weil plantea a propósito de la vida en las ciudades como un «arraigarse en la ausencia de lugar », releída desde su condición de migrante globalizado. Esta idea de Neuman resulta sugerente, máxime cuando precisa que ese tránsito lleva aparejada una pregunta por la identidad. A fin de cuentas, la literatura llama la atención acerca de algo hoy evidente al resto de actores que constituimos el campo : resulta imposible pensar la literatura latinoamericana sino como una convención, y a las literaturas nacionales si no es leyéndolas desde la conciencia del 
resquebrajamiento de los Estados nación fruto del transnacionalismo económico y político o la heterogeneidad cultural propia de la globalización.

2 Cornejo Polar apuntaba a cuatro instancias que se deben tomar en cuenta a la hora de pensar la heterogeneidad cultural : la producción del texto, el texto mismo, su referente y el sistema de su producción y su consumo ${ }^{4}$. Acaso esas cuatro instancias sirvan para pensar los niveles o ámbitos a partir de los cuales se vinculan las literaturas de la globalización con los territorios. Hoy, encerrar la literatura de cualquier autor en un sistema de producción, circulación y referencialidad temática nacional sería imposible, y una parte importante de la ficción latinoamericana reciente puede pensarse desde la metáfora de lo desterritorializado. Pero, si es cierto que la globalización desesencializa los vínculos entre territorio y sentido de pertenencia, ¿se halla el lugar predominantemente ausente en la última narrativa latinoamericana?

La literatura en tiempos de globalización puede decirse en alguna medida " heterogénea ", en tanto se halla signada por «la duplicidad o pluralidad de los signos socioculturales de su proceso productivo [...] que tiene por lo menos un elemento que no coincide con la filiación de los otros y crea, necesariamente, una zona de ambigüedad y conflicto $»^{5}$. Esta heterogeneidad supone efectivamente una desterritorialización y, a la vez, la asunción de una multiplicidad o una multiplicación de los contextos. Por eso, tal vez habría que prevenirse contra un uso inflacionario de la idea de lo desterritorializado o extraterritorializado en estos tiempos de migraciones masivas e hipercomunicación ${ }^{6}$. El esfuerzo por arraigarse en esa ausencia de lugar en que deviene la vida cotidiana hoy nos habla de un proceso que se da en términos de una dialéctica entre desterritorialización y reterritorialización. Inclusive, el debate se da de forma intensa acerca de en qué medida se puede pensar la red internet como un espacio completamente desterritorializado. Aunque, desde luego, puede simularse su desaparición, los contextos locales la mayor parte de las veces no desaparecen por completo ni siquiera en los nuevos media, sino que penetran en el espacio digital desterritorializado, produciéndose una vecindad y una permeabilidad nueva de los territorios ${ }^{7}$.

4 Antes que en ficciones completamente desterritorializadas -en lo que respecta al texto mismo o su referente como partes de su proceso productivo heterogéneo-, mucha de la ficción contemporánea, particularmente en Uruguay, apunta antes que a una desterritorialización a una "multiterritorialidad», que las obras transcriben, sea ésta fruto de una experiencia «real» de deslocalización transnacional o de una multiterritorialidad « imaginada $»^{8}$.

5 A esta multiterritorialidad imaginada responde en particular la novela de Ramiro Sanchiz, La vista desde el puente (2011). A partir de su análisis, reflexionaremos acerca de algunas características de la ficción uruguaya reciente y plantearemos finalmente un corpus para un estudio ulterior en curso.

\section{Apuntes sobre última narrativa uruguaya}

Ramiro Sanchiz (1978) pertenece ya a una nueva promoción de autores postcrisis de 2002, que empieza a publicar entrado el siglo XXI y que comienza a gozar de la atención de la crítica desde fines de la década pasada. 2008 es un año clave. Al menos tres antologías de diferente naturaleza y con diferente criterio de selección, recogen ese año una colección de nombres nuevos que apenas habían tenido repercusión anteriormente (El descontento 
y la promesa ${ }^{9}$, De acá $!^{10}$ y Esto no es una antología ${ }^{11}$ ). La reiteración de ciertos nombres en las mismas termina dando visibilidad a una serie de escritores que hoy ya han publicado una obra de cierta extensión, entre dos y cuatro títulos. Uno de sus primeros antólogos, Hugo Achugar, premunido de las lógicas cautelas en lo que respecta a la validez del concepto de "generación ", señala que puede hablarse de un grupo de escritores nacidos entre los setenta y ochenta, que crecieron bajo la dictadura y el posterior advenimiento democrático, y a quienes se les despierta la vocación en los noventa, con el desarrollo del neoliberalismo en Uruguay. En opinión de Achugar, la generación del nuevo siglo se desvincula de la historia nacional como factor determinante de su quehacer artístico: «Cuando nacieron o cuando eran niños la dictadura estaba terminando o comenzando a convertirse en una historia que pertenecía a sus padres y abuelos. Una historia que los interpela como ciudadanos, pero que no necesariamente los convoca como artistas $»^{12}$.

7 Esta generación post-2002, que escritores como Sanchiz prefieren asociar al 2008, se ve beneficiada por el desarrollo de nuevas políticas culturales a cargo de la izquierda uruguaya, el aumento de la inversión pública, en forma de subvenciones y premios ${ }^{13}$, y nuevas editoriales que surgen en estos años. La intervención sin duda más importante es la que acaudilla Martín Fernández, desde 2008, editor de $\mathrm{HUM}^{14}$, con sus colecciones paralelas Estuario y Cosecha Roja, recogiendo el testigo de las desaparecidas Artefato y Amuleto, que codirigió junto al poeta Leandro Costas. En 2009 aparece la editorial La propia cartonera, en el humilde barrio de la Teja, dirigida por el también poeta Diego Recoba. Otro escritor, Gabriel Sosa, que había trabajado con Cauce, funda otra editorial, Irrupciones grupo editor ${ }^{15}$. Junto con Trilce, que mantiene una colección de narrativa uruguaya que da cabida a los jóvenes, y Banda Oriental, ocupan el espacio que dejaron las grandes multinacionales españolas que abandonan los riesgos por razones de cuota de mercado. Esta encrucijada de final de década también ha dado cabida a relecturas de autores que habían escrito obras valiosas en los noventa y que en la nueva década se habían diluido o habían encontrado dificultades para publicar. Reaparecen en nuevos sellos Mercedes Estramil, Daniel Mella ${ }^{16}$, Henry Trujillo, Pablo Casacuberta o Gabriel Peveroni. Junto a ellos gozan de una nueva juventud otros autores mayores aún, aunque no consagrados anteriormente, como Amir Hamed, Álvaro Ojeda, Gustavo Espinosa y Carlos Rehermann. Y por último, Felipe Polleri, una figura inclasificable que cuesta vincular más que consigo misma, si acaso, con la tradición a la que accedemos a través de Levrero ${ }^{17}$. Parece unánime la revalorización en el canon, sobre todo tras su muerte, del último maestro secreto de la literatura uruguaya, como es Levrero ${ }^{18}$, quien, si bien influye directamente en unos pocos, puede afirmarse que supone una figura tutelar para la gran mayoría de jóvenes. Como le ocurre a Aira en Argentina a su modo ${ }^{19}$, Levrero es el dispositivo óptico con el que los jóvenes releen la literatura nacional.

En 2009 el crítico Gabriel Lagos hace por primera vez un intento de sistematización de la ficción más reciente ${ }^{20}$. Divide a los nuevos narradores desde los dos mil en tres grupos. Los pop, por un lado, que reciclan estrategias camp en la tematización de la contaminación creciente del imaginario en la era de la saturación mediática, entre los que podríamos destacar, con diferente suerte, a Natalia Mardero (1974), periodista, autora del volumen de cuentos Posmonauta (2001) y la novela Guía para un universo (2004), a Ignacio Alcurí (1980), conocido como presentador de televisión, también cultor del género breve en Sobredosis pop (2003), Problema mío (2007) o Temporada de Pathos (2010), en cuya propuesta, quizás la más comercial, es una marca central el humor, o a Dani Umpi (1975), autor de las 
novelas Miss Tacuarembó (2004), versionada como largometraje en 2010, Aún soltera (2003) y Solo te quiero como amigo (2006) ${ }^{21}$.

Otro grupo es el formado por los « egotistas » o « intimistas », siguiendo la terminología de Lagos, llamados también por el crítico Ignacio Bajter -despectivamente en su caso«levreristas $»^{22}$, pues muchos de ellos fueron talleristas de Levrero. El grupo se caracterizaría por plantear textos híbridos en su mayoría entre la autoficción y la autobiografía, en los que el espacio social representado se vuelve telón de fondo para una exploración de la interioridad o los recuerdos infantiles, tejiendo atmósferas extrañadas de un realismo oblicuo que no llega a ingresar en lo fantástico, donde Salinger o Carver son algunas referencias reiteradas ${ }^{23}$. En este grupo Lagos cita a mujeres, en su mayor parte. Inés Bortagaray, con Prontos, listos, ya (2006), el relato desde la óptica de una niña de un viaje familiar en coche a Salto que hace de ese coche el microclima en que sucede la novela ; Patricia Turnes (1971), que publicó la novela Pendejos (2007), una investigación psicológica de la crisis personal y laboral de su generación fin de siglo, relativamente autobiográfica, que además ficcionaliza a Levrero como personaje ; o Sofi Richero (1973), autora de la novela Limonada (2004). Podríamos añadir algunos hombres que pasa por alto Lagos, pero que están en la órbita levreriana : Pablo Silva, director en la radio pública de Montevideo del programa cultural La máquina de pensar ${ }^{24}, y$ que publicó el libro de relatos Entrar en el juego (2007), o Alejandro Ferreiro (1968), autor algo mayor aunque solo acabará publicando en el año 2000 su novela Portland $(2000)^{25}$. En este grupo destaca Fernanda Trías (1976), autora de La azotea $(2001)^{26}$, tal vez la novela más relevante de esta veta intimista y quizás la mejor del siglo XXI en Uruguay. Ciertamente, buena parte de estos autores acudieron a alguno de los talleres de Levrero. Pero los talleristas de este autor, que buena parte de su vida hizo de los talleres su trabajo más conocido, son legión y no necesariamente se adscriben a su estética. Por otra parte, como señala Sanchiz ${ }^{27}$, los autores más estrechamente vinculados a la figura tutelar de Levrero no exploran en sus obras lo fantástico de su primer período, sino que proponen textos influidos del biografismo y las escrituras del yo de su última producción (El discurso vacío o La novela luminosa).

Un tercer grupo lo compondrían autores que puede decirse que son plenamente conscientes del diálogo que mantienen con diferentes estratos de la cultura letrada nacional, o que buscarían centralmente ese diálogo. El yo pierde fuerza y la narración regresa a la tercera persona. Autores de ficciones que presentan ciertos guiños onettianos y borgianos, en algunos casos, en otros, influidas del realismo sucio de la generación previa, aunque dejándose seducir por lo fantástico y, en ocasiones, la ciencia ficción (Philip K. Dick o J.G. Ballard, sobre todo), la gran mayoría de los reunidos en este grupo despliegan una veta metafictiva que es la marca más representativa de sus propuestas. Una orientación literaria o culturalista que se irradia, además, en ciertos casos, a partir de una visibilidad mediática en su rol de críticos $^{28}$. Esta presencia crítica, creo, confabula en la construcción de una entidad colectiva que defiende su acceso al canon. En este grupo, que Lagos denomina como "los serios» (Lagos, 2009), por su "exigencia formal», cuidado de la "arquitectura narrativa " y «trabajo con el lenguaje ${ }^{29}$, cita en exclusiva escritores varones. Entre ellos Horacio Cavallo (1977), poeta, autor de las valiosas novelas Oso de trapo (2008) y Fabril (2010), inspirada en su experiencia personal como trabajador en una empresa automotriz. Gabriel Schutz, afincado en México, autor de los volúmenes de relatos Una noche de luz clara y otros cuentos (2001) e Y verás mis espaldas (2006), y de la novela Rapsodia nocturna (2008). Agustín Acevedo Kanopa (1985), el más joven, autor de la 
novela Antes del crepúsculo (2010). Andrés Ressia (1977), el autor de mayor proyección internacional del grupo, que figuró en la conocida lista de 22 autores jóvenes de la revista Granta y es autor de las novelas Palcante (2007) y Parir (2009). Si respetamos la etiqueta de Lagos habría que incluir en el grupo a Martín Arocena (1979), autor de la novela Exiliados (2011), recorrido culturalista por la biografía ficcionalizada de doce artistas universales precisamente en coyunturas de exilio o desterritorialización, una ficción que muestra la distancia mayor con respecto a las escrituras autobiográficas de los que Lagos llama " egoístas " ${ }^{30}$.

11 Coincido con Sanchiz cuando añade a estos tres grupos un cuarto formado por autores que comparten rasgos con alguno de los anteriores pero que, hasta ahora, exploran en exclusiva la literatura de género ${ }^{31}$. Dedicados al policial encontraríamos a Germán Videla (1974), con George el sapo (2006), un original texto noir protagonizado por animales de todo cuño, Rodolfo Santullo (1979), autor de Cementerio norte y Sobres de papel manila (2011), o Pedro Peña (1975), autor de La noche que no se repite (Lima, 2010); o el fantástico, como el propio Peña hace con los relatos de Eldor (2006), y Damián González Bertolino (1980), con El increible Springer (2009) y Threesomes (2009) ; por último, la ciencia ficción más estricta, como ocurre con Pablo Dobrinin (1970), que reúne sus cuentos dispersos recientemente en el volumen Colores peligrosos (Buenos Aires, 2011). Ello no quiere decir que el resto no presente un gusto por lo subgenérico, de hecho es una nota común en alguno de los autores arriba mencionados. Convendría pensar, sugiere Sanchiz, en espacios híbridos entre los grupos descritos. Así, el poeta y narrador Jorge Alfonso, celebrado por Lagos como uno de los -quizás no muy afortunadamente llamados- "serios ", en sus cuentos de Porrovideo (2008) combina una fuerte referencialidad pop con la exploración de la ciencia ficción. En este mismo sentido cabe referirse a Sanchiz, que se aproxima a la ciencia ficción como uno de los más brillantes y prolíficos pese a su juventud. Sanchiz ha publicado hasta la fecha las novelas 01. Lineal (2007), Perséfone (2009), Nadie recuerda a Mlejnas (2010), La vista desde el puente (2011), las novelas cortas Trashpunk (2012) y Vampiros porteños, sombras solitarias (2010), y los libros de relatos Algunos de los otros (2008) y Los viajes $(2012)^{32}$. Su obra está atravesada por la borgiana intuición de senderos que se bifurcan en universos paralelos, que se abren en cada uno de sus relatos y se cierran a su término. Todos ellos protagonizados por Federico Stahl, suerte de alter-ego del autor que muta levemente en cada uno ${ }^{33}$.

\section{Transgresión geográfica y reconstrucción del imaginario}

Si el imaginario de una nación se ha de entender como un conjunto de significaciones, discursos y representaciones que totalizan el campo de una determinada experiencia, uno de los más sólidos imaginarios del Uruguay vigente desde fines del siglo XIX y a lo largo del pasado siglo, ha girado en torno al mito de la « Suiza de América ». Un mito articulado en torno a dos mitologemas básicos: primero, el de la «medianía ", constituido a partir de la idea de un Estado Benefactor, garante de la estabilidad social y el bienestar, y un consenso general en el respeto a la democracia. Y, segundo, el mitologema de la diferenciación, que construye lo uruguayo por una triple oposición (no ser estadounidenses, no parecer "latinoamericanos", no ser europeos aunque sí pareciéndolo) ${ }^{34}$. Esta autoimagen inicia su crisis a mediados de siglo, pero estalla fundamentalmente con la dictadura del 73 , primero $\mathrm{y}$, después, con las políticas 
neoliberales en los noventa. En este sentido la inmigración como elemento configurador de la identidad como país de acogida, deja paso al exilio y la emigración, elementos configuradores de una nueva identidad de país que expulsa a sus ciudadanos ${ }^{35}$. El mito del Uruguay como "país de inmigrantes", crisol de naciones o "nación trasplantada $»^{36}$, que fundó la autoimagen de la «Suiza de América», se ha vuelto insostenible. Una constelación de textos culturales de entre siglos da muestra de ello, tanto en la música, el cine ${ }^{37} \mathrm{y}$, por supuesto, la literatura. En la última narrativa uruguaya entonces encontramos una particular proliferación de narrativas de temática tendente a lo centrífugo, que narran la experiencia migratoria transnacional en los dos miles, pero también de temática centrípeta ${ }^{38}$, que regresa sobre el territorio en novelas en muchos casos centradas en la derrisión de los horizontes de expectativas de las clases medias aisladas de una posible identificación con las señas de identidad previas, reflexionando e interviniendo sobre cómo se han venido transformando los imaginarios en contextos crecientemente transnacionales.

puente supone una modulación interesante en este último grupo, en la medida en que, para cuestionar el imaginario nacional, invierte la visualización del Uruguay como una porción desgajada de la Argentina que late en los prejuicios populares y en las referencias letradas a Uruguay como « la Banda Oriental » desde el otro "país hermano ». La novela propone el cuestionamiento de los límites del territorio uruguayo fantaseando una supuesta incorporación de la provincia de Corrientes al Uruguay. El sempiterno Federico Stahl, un joven escritor inmerso en un período de sequedad creativa desde la publicación de su celebrada primera novela, Desintegración ${ }^{39}$, viaja del otro lado del Río impulsado por la noticia del reciente suicidio de Rafael, su padre, profesor de historia en la Universidad correntina y reconocido biógrafo de José Gervasio Artigas. El padre, con el que Federico había roto lazos en vida, tiende un puente al hijo proponiéndole por escrito entregarle en herencia su biblioteca a cambio de concluir la investigación que tenía entre manos cuando se quitó la vida. Lo llamativo de ese ingreso fantástico a la «República Anfiuruguaya » que propone Sanchiz radica en que, para penetrar en el juego de secretos que se espejean en la figura del padre y en la de Artigas, haya que salir de "esa vieja casona venida a menos " $^{40}$ que es Montevideo, una vez más, salir al exterior del país para ingresar en él, rehacer su silueta, atravesar un puente que destruye la autoimagen de una nación que impide que se la pueda ver.

La ucronía de Sanchiz, un relato contrafáctico que plantea la posibilidad de que el proyecto artiguista haya tenido éxito, encuentra un punto en la historia desde el que hacer arrancar una línea temporal divergente. En este universo paralelo Andrés Latorre avisa a Artigas de la posible derrota en la Quebrada de Belarmino y le sugiere que aguarde con su ejército en Tacuarembó, evitando la derrota artiguista ante las tropas portuguesas en 1820. El exilio de Artigas en Paraguay nunca tuvo lugar. Por el contrario, éste se erigió en el primer tirano de una « República Anfiuruguaya » independiente, hasta su muerte en 1850. Después de esa fecha sobreviene una «Guerra de Sucesión » y un enfrentamiento armado con Rosas, que termina haciendo perder a Uruguay los territorios de Córdoba y Entrerríos. El país que sobrevive en el presente de la novela queda polarizado en torno a dos ciudades antagónicas, Montevideo y Corrientes.

La ucronía se hibrida en la novela con el policial. A los interrogantes que abren el suicidio de un padre ausente, que se marchó a Corrientes durante su infancia para formar otra familia, y la investigación histórica inconclusa sobre los últimos años del "Mandato », una fantástica dictadura de Artigas, se añade una segunda investigación policial en curso 
relativa a unos asesinatos en serie de indios charrúas, con la que de alguna manera se halla vinculado su propio padre. Por un lado, una de las víctimas fue una india guenoa amante de su padre, por otro, en todos los cadáveres aparece una misma marca a fuego, un símbolo teosófico que la novela vincula a grupos nazis « blancosuprematistas ». Su uso queda documentado en los últimos años del Mandato, en torno a los cuales circula una leyenda negra relativa a la supuesta locura del Prócer. La novela se suma a una serie de relatos de temática artiguista que precisamente en el año del Bicentenario aparecen, postulando de algún modo la desmitificación de la figura del Prócer a cargo del discurso oficialista ${ }^{41}$. Pero me interesa destacar que el texto de Sanchiz, más allá del oportunismo de la fecha ${ }^{42}$, imagina un conflicto intercultural en un Uruguay que resulta de un recorrido alternativo de la historia nacional, y lo interesante es que en él se acentúan unos prejuicios que la citada narrativa del «pueblo trasplantado » tiende a sepultar. $L a$ vista desde el puente trabaja a partir de una sintomatología común en la cultura uruguaya del nuevo siglo : la reetnización de la identidad.

\section{Una historia reetnizada}

17 La globalización y, particularmente en Uruguay, la intensificación de los flujos migratorios desde 2001, ha repercutido en una creciente transnacionalización del imaginario. Por un lado, se asiste a « una territorialización con respecto al afuera del nosotros $»^{43}$, se nacionaliza la diáspora o se la integra en una imagen nueva de lo nacional que trasciende el territorio, por otro lado, se da un proceso simultáneo de «desterritorialización y multiterritorialidad hacia adentro del grupo nacional $»^{44} . \mathrm{Y}$ esa multiterritorialidad implica la visibilidad de una multiculturalidad ya no asociada primordialmente a la imagen del Uruguay como « Suiza de América », sino, ahora, tanto a una nueva multiterritorialidad vinculada a los destinos geográficos de la diáspora reciente, como al cuestionamiento de la homogeneidad social constitutiva de la imagen tradicional del país. Así, la globalización también genera una serie de narrativas identitarias centrípetas, que intervienen en el debate en curso acerca de qué tipo de país de inmigración se fue, y qué tipo de país se quiere (o no) ser. Y este es el caso, me parece, de la novela que analizamos.

Raymond Williams había establecido una diferencia entre lo " arcaico », lo « residual » y lo "emergente" para subrayar que todo legado cultural siempre es un proceso en movimiento constante ${ }^{45}$. Lo " arcaico " es lo que pertenece al pasado y es reconocido como tal por quienes hoy lo reviven, casi siempre de modo especializado. Lo "residual» alude a aquello que se formó en el pasado pero todavía se halla en actividad dentro de los procesos culturales. Finalmente, lo "emergente » designa los nuevos significados y valores, nuevas prácticas y relaciones sociales. En casi todos los casos de reetnización ${ }^{46}, \mathrm{o}$ renacionalización ${ }^{47}$, en tanto reconfiguración de los imaginarios, aspectos aparentemente "arcaicos" pasan a constituir un repertorio de símbolos que se reactivan y se resemantizan en el campo de lo emergente. Esto ocurre en la cultura uruguaya recientemente con la recuperación de elementos y tradiciones vinculadas a lo afrouruguayo y con la visibilización del patrimonio indígena que tanto el Estado como parte de la sociedad civil han venido fomentando.

19 La transgresión del imaginario geográfico en la novela de Sanchiz sirve de punto de partida para la reelaboración de una historia reetnizada, planteando una realidad paralela multicultural donde la civilización charrúa no fue exterminada. Corrientes y sus 
alrededores son el espacio donde los "pueblos originarios " se asientan. Allí los indios dejan de integrar una reserva simbólica: existe un cierto grado de bilingüismo, los carteles anuncian "información en castellano, charrúa y guaraní " ${ }^{48}$, los charrúas se asocian en colectivos como el «Partido de Acción Originaria »"4, o el «Grupo de Acción Poética Renacimiento Charrúa $»^{50}$, intervienen en la vida política y se convierten en una presencia palpable en las calles :

La gran estatua del Padre de la Patria que se levantaba en la plaza central, [...] estaba cubierta de óxido verde y grafitis que parecían un campo de batalla entre blancosuprematistas y originarios, charrúas y guaraníes, guenoas y chanaes. Alguien había escrito Orientales putos en rojo por encima de un enorme gusanos que aparecía firmado por un acrónimo que Federico no entendión ${ }^{51}$.

Si obviamos el pacto básico de lectura con la cuántica como telón de fondo ${ }^{52}$, la ucronía de Sanchiz mantiene un verosímil que elude lo maravilloso y lo fantástico de acuerdo a la definición que de ellos da Todorov. Aunque en las descripciones y observaciones que el narrador nos da del universo que dibuja con frecuencia se leen referencias al esqueleto de la ciencia ficción. Esta retórica de género subraya la artificialidad o irrealidad del espacio a los ojos del protagonista, al tiempo que refuerza la descripción del decaimiento del presente, pintado en términos postapocalípticos. Así, el viaje a Corrientes para Federico Stahl significa un salto en el tiempo: «al bajar del ómnibus [sintió] que funcionaba allí una suerte de vórtice espaciotemporal capaz de llevarlo ciento cincuenta años al pasado " ${ }^{53}$. De igual modo, su experiencia en la terminal de autobuses se narra según esa retórica que se sostiene siempre que pone sobre el tapete la perspectiva del protagonista sobre la realidad : « las columnas y arcos y ojivas que se cerraban en torno a Federico remitían a tiempos previos a la Atlántida y Lemuria, a la época de los hiperbóreos, un mundo conformado por un único bosque interminable que mordía las orillas de la realidad $»^{54}$.

21 La percepción fantástica de la realidad a los ojos del personaje, un joven de Montevideo en los dos miles, casa con la negación oficialista de la visibilidad indígena, camuflada una vez más como una narrativa de modernidad. Esta negación se repite en la novela a pesar de hallarnos en un universo alternativo y de ambientarse la ficción en el siglo XXI, no en el XIX. Si el Uruguay real vive en la negación de su pasado histórico, la desconexión que imagina la novela afecta al propio presente que queda del lado opuesto del Río :

En el liceo le habían repetido hasta el cansancio que Uruguay tenía dos polos: Montevideo, que representaba las presuntas conquistas de la modernidad y la cultura europea, y Corrientes, último bastión de aquel país de indios derrotado por el avance de la Iglesia y Occidente ${ }^{55}$.

Así se lo hace ver Federico a Viera, académico amigo de su padre, cuando este le muestra una estampita del «Cristo Indio », iconografía que data de tiempos de Artigas, y le habla del uso de sustancias psicoactivas por parte de algunas comunidades indígenas :

-No tenía idea... en Montevideo es muy fácil percibir a los charrúas como una entidad única, homogénea... y recientemente revivida o imaginada. Como si alguien hubiese creado un pueblo hace veinte años. Les otorgaron un pasado falso, una lengua artificial [...] da esa sensación... fantasmal ${ }^{56}$.

Frente al colectivo originario, con una presencia material en el Uruguay ficticio de la novela, surgen grupos «blancosuprematistas » a los cuales pertenecen algunos miembros de la Sociedad Artiguista de Corrientes. Más allá de los crímenes referidos, la novela no sigue los derroteros de una reflexión sobre la cuestión del mestizaje. Salvo las referencias a la amante indígena de Rafael o al poeta charrúa Inchala Pirú, ambos finalmente asesinados, los personajes intervinientes en la trama son de hecho blancos. Se centra por 
el contrario en cómo esa presencia indígena -y los conflictos interétnicos que se vislumbran- desmontan la autoimagen homogénea del Uruguay real. La imagen de un Artigas histórico defensor de los indios, que contó entre sus ejércitos con guaraníes y charrúas y tuvo una guardia próxima siempre a él de unos veinticinco indígenas ${ }^{57}$, es objeto de la desmitificación novelesca. Lo que descubre Stahl en último término al atravesar el puente que lleva al mundo de su padre es que este también perdió la fe, pasando a ser un completo descreído del trabajo que había venido edificando. Tal vez, se nos sugiere en la novela, la muerte de su amante india y su aparente suicidio estén relacionados con ese descubrimiento. Rafael, a partir de una fotografía post-mortem que le realizan a Artigas, llega a descubrir indicios de los vínculos fehacientes del dictador con un proyecto de exterminio indígena. Federico lee y ordena, para una clase magistral en la universidad correntina, la última conferencia que su padre dejó en borrador, a partir de sus propios descubrimientos. En ella se nos revela que Artigas cobijó sociedades secretas racistas vinculadas con asesinos en serie, como Isidoro Ducasse, y dejó firmada la orden que habría llevado a un genocidio similar como el que tuvo lugar en la historia real, a cargo de Fructuoso Rivera, responsable de la matanza decisiva de Salsipuedes, en 1831.

Se tematiza aquí el encubrimiento de la herida colonial, con la ficcionalización de un discurso de lo que Mignolo llamaría un « pensamiento fronterizo débil $»^{58}$, que cuestiona en el siglo XXI toda posible identificación con la autoimagen de "país de inmigrantes » europeos o de una clase media relativamente homogénea, e interpela también a ese país otro, ideado por la imaginación ucrónica, volviendo la narrativa identitaria articulada en torno al prócer en una falacia :

Nos hace preguntarnos quiénes pautaron el engaño que lo enmascaró, que lo censuró ; nos hace mirarnos al espejo y preguntarnos quiénes somos. En cuanto uruguayos. En cuanto orientales o entrerrianos o gaúyos, en cuanto montevideanos, rosarinos, correntinos, portoalegrenses, salteños, en cuanto criollos, en cuanto hijos de inmigrantes, en cuanto guenoas, chanaes, yaros o bobanes. En cuanto esos que aceptaron la mentira y siguieron a quienes la crearon y dosificaron, disolviéndola en la leche con que se alimenta a los niños ${ }^{59}$.

El Uruguay, mirado desde el puente, no puede ser otra cosa que " un fantasma », " un caos de representaciones ordenado por alguna forma de poder $»^{60}$. La terrible posibilidad que vislumbra Rafael, la del exterminio y su olvido, no es más que la moneda de uso corriente en la realidad real, de un país que exterminó a sus originarios e invisibilizó por largos años sus tradiciones. La vista desde el puente, al menos en esa conferencia escrita a cuatro manos proyecta, sobre el presente de generaciones de "ciudadanos del mundo », una mirada posnacionalista, el deseo de ir más allá de la nación como salida utópica :

[...] sólo podemos dar la espalda a ese orden [...] arrasando el campo sobre el que fueron levantadas las ciudades y comenzando de nuevo. Reconstruyéndonos. Reinventándonos. Señalando a esos que nos han conducido aquí y diciendo : no somos así. Así no queremos ser. Dando la espalda a la historia y plantándonos en el presente, en nuestro presente, [...] Porque si Uruguay es lo que nos han enseñado, si Uruguay es una mentira que encubre la infamia, si Uruguay es la monstruosa ramificación de esa infamia, entonces, reneguemos de ese país erigido desde la mentira. Una vez más : no somos así, así no queremos $\operatorname{ser}^{61}$.

La derrisión de la narrativa identitaria es puesta en boca de los personajes, o mejor, en la voz de Federico, donde resuena el eco de la de su padre. La conferencia, « un monstruo de Frankenstein $»^{62}$, significa el establecimiento de una tímida conexión paterno-filial, un puente, aunque sea para concluir la invalidez de la Historia nacional. Esa posible reconciliación con un padre que la Historia con mayúsculas le había arrebatado es la 
tímida salida utópica, intersticial, una vez más sugerida según una retórica que proviene de la ciencia ficción. El juego de pistas que le propone Rafael a Federico termina con una carta, tal vez una fotografía, escondida en un libro de su padre. Refiere un recuerdo compartido, en la infancia de Federico, en un lugar que es una vez más imaginario, como el lugar de la utopía desde que la ideara como género Tomás Moro. En Sanchiz ese lugar está localizado en un punto difuso del Uruguay, Punta de Piedra, suerte de concentrado de diferentes balnearios de Rocha :

Aterrizan en la arena fina y seca y giran, siguiendo la pequeña pendiente de las dunas a escala. ¡Nos hacemos milanesa, nos hacemos milanesa! Grita Federico y su padre se ríe a carcajadas y lo toma del brazo. Algo se ha clavado en su brazo. Rafael, sorprendido, lo examina, le sacude la arena. Hay un bicho moribundo pegado a su hijo : una abeja o una avispa. Mirá, le dice, te picó una abeja. Federico no puede creerlo : ¿estaba ahí, en la arena, sin volar, sin hacer nada, y yo justo caí sobre ella? Su padre asiente. ¿Pero no es medio raro ?, le pregunta el niño. Es sí, le responde Rafael, pero, ¿sabés ? Esto es Punta de Piedra : acá todo, todo es posible ${ }^{63}$.

Si la forma de la utopía para Rafael es la afirmación en la negación como nuevo comienzo - «así no queremos ser » ${ }^{64}$ - con su contracara distópica, que es la negación de lo que se es a partir del suicidio, para el hijo, Federico, la identidad ya no puede enunciarse en plural. La forma intersticial de la utopía se abre acaso a la posibilidad de alcanzar esa otra orilla, ubicada en ese lugar inexistente, donde el presente pueda reconciliarse con el pasado personal, tal vez en una isla al margen de la Historia. Si lo posnacional se vislumbra como utopía, finalmente, la posibilidad de sacudirse como la arena de la piel una determinada narrativa identitaria que oblitera la ignominia, esa misma ignominia, también nos señala la novela, nos marca. Federico es en un momento apresado por Reyles, líder blancosuprematista, siendo torturado y marcado con un hierro incandescente en el brazo. Federico deja escapar esa nota o esa fotografía de él y su padre, juntos, por la ventanilla del ómnibus. La novela concluye con un viaje de regreso, y la anagnórisis de un personaje que se reconcilia con parte de su identidad, el mismo es a fin de cuentas una fuga a un espacio imaginario, Punta de Piedra. Sabemos, como en el fondo lo sabe Deckard cuando se fuga con la replicante al término de Bladerunner, que la Historia nos alcanza, se pega a nosotros, como un « bicho moribundo », como un tatuaje a fuego a nuestro brazo.

\section{Algunas conclusiones : de la «Banda Occidental » de la República Anfiuruguaya a la reconfiguración del imaginario}

28 La multiterritorialidad, en tanto continuo proceso de desterritorialización y reterritorialización, caracteriza las identidades sujetas a diferentes procesos de transnacionalización cultural en nuestro presente. En la novela de Ramiro Sanchiz la tematización de una crisis de la idea de pertenencia se acompaña de una multiterritorialidad, con la cooptación del espacio geográfico perteneciente a Argentina, y su inserción en la geografía política uruguaya que sirve de recurso para la reetnización de la historia nacional. El discurso ucrónico invierte la cooptación del imaginario uruguayo que resulta frecuente en la cultura Argentina, que ha mirado tradicionalmente hacia Uruguay como una provincia desgajada, la «Banda Oriental». De este modo Corrientes deviene en una suerte de Banda Occidental del Uruguay. La novela visualiza geográficamente esa multiterritorialidad, que es «imaginada», en la medida en que 
afecta a sujetos que escriben en el interior de sus países desde una experiencia de globalización tecnológica e hibridez cultural, pese a no vivir de facto entre dos o más contextos, como sí les ocurre a muchos migrantes transnacionales. Esta multiterritorialidad «real» o «imaginada » me parece clave en la obra de las últimas promociones de autores. Y resulta particularmente interesante a la hora de pensar la última narrativa uruguaya, de la que esta novela constituye un ejemplo.

Si los noventa habían asistido en Uruguay a un cuestionamiento de la identidad nacional a cargo de la inteligentsia académica, los dos miles, tras el estallido de las narrativas identitarias nacionales con la crisis de 2002, abren ese cuestionamiento a la heterogeneidad constitutiva de una nación que ha vivido de espaldas a sus minorías invisibilizadas ${ }^{65}$. La vista desde el puente resulta sintomática de cómo una parte de la ficción uruguaya del presente siglo vuelve sobre la nación, ya sea como en este caso para narrar la derrisión de sus imaginarios (el de una "Suiza de América » ahora reetnizada), en ficciones interesadas en la forma en que se construyen o se han construido las narrativas identitarias colectivas. Explorando los modos de posibilidad e imposibilidad de reconocimiento en esas narrativas identitarias, la novela de Sanchiz interviene en el proceso de transformación de los imaginarios colectivos en tiempos de globalización. Y se abre, finalmente, a una utopía intersticial ${ }^{66}$ que se disuelve, como esa nota o imagen que se deja ir por la ventana del ómnibus durante un viaje a un lugar imaginario.

Concluyo este artículo apuntando un corpus para un estudio más amplio, que podría reunir las obras de diferente cuño de Mercedes Estramil, Hispania Help, Ana Vidal, Frankfurt, Andrea Blanqué, Atlántico, Mariana Casares, Sex Shop no es pecado, Gabriel Peveroni, El exilio según Nicolás y Tobogán blanco, Pablo Casacuberta, Escipión, y, finalmente, ésta de Ramiro Sanchiz. En todas estas novelas se explicita más o menos centralmente una reflexión acerca de la reconfiguración de los imaginarios nacionales desde diferentes acercamientos que podríamos catalogar como posnacionalistas o, mejor, transnacionalistas, pudiéndose leer como novelas-síntoma de la reconfiguración transnacional de la significación cultural del territorio en tiempos de globalización.

\section{NOTAS}

1. Cit. en F. Aínsa, Palabras nómadas, nuevos centros de la periferia, Alpha, nº 30, julio 2010, p. 55-78. Ideas que Aínsa ha continuado explorando en su ensayo reciente Palabras nómadas: nueva cartografía de la pertenencia, Madrid, Iberoamericana, 2012.

2. A. Neuman, « Pasaporte de frontera », en F. Noguerol, M.A.Pérez, A.Esteban y J. Montoya (eds.), Literatura más allá de la nación : de lo centrípeto y lo centrífugo en la narrativa hispanoamericana del siglo XXI, Madrid, Iberoamericana, 2011, p. 199-207.

3. Idem, p. 205.

4. En A. Cornejo Polar, «El indigenismo y las literaturas heterogéneas: su doble estatuto sociocultural ", en Arte, literatura y crítica latinoamericana, Universidad Central de Venezuela, Caracas, 1982, p. 67-85.

5. A. Cornejo Polar, op.cit., p. 74-75. 
6. Véase Á. Esteban y J. Montoya, «¿Desterritorializados o multiterritorializados ? : la narrativa hispanoamericana en el siglo XXI », Francisca Noguerol et al. (eds.), Literatura más allá de la nación, Madrid, Iberoamericana, 2011, p. 7-13.

7. Si pensamos en un muro de facebook donde nuestros contactos cuelgan información podremos ejemplificar bastante claramente cómo los territorios ingresan a un espacio virtual aparentemente desterritorializado. Al leer un «muro » o una «biografía » podemos conocer el estado personal de un contacto, las noticias o cuestiones de interés que transcurren en sus países o ciudades de origen, o en el resto del mundo, filtrados por su criterio de selección, al tiempo que podemos ver vídeos y fotografías de lugares dispares, y las fotografías tomadas por el individuo en espacios geográficos concretos en los que transcurre su cotidianidad. De tal manera que habría que pensar, inclusive en este espacio donde ni siquiera la interacción humana se produce bajo parámetros cartesianos y la identidad subjetiva deviene en posthumana, en una multiterritorialidad virtual donde la idea de lo local no se disuelve del todo sino que se reconstituye en un nuevo marco.

8. N. Moraes Mena, Transnacionalismo político y nación : el papel del estado y la sociedad civil migrante en la construcción de la trans-nación uruguaya, (tesis doctoral), Universidad de Granada, 2010 http:// hdl.handle.net/10481/4927

9. H. Achugar (ed. y prólogo), El descontento y la promesa: nueva/joven narrativa uruguaya, Montevideo, Trilce, 2008.

10. P. Trochón (comp. y prólogo), De acá !, algo de narrativa joven uruguaya de ahora, Montevideo, Rebeca Linke editoras, 2008.

11. H. Bernardo (ed. y prólogo), Esto no es una antología : antología de narradores jóvenes uruguayos, Montevideo, Ministerio de Relaciones Exteriores-ORT, 2008.

12. H. Achugar, « El descontento y la promesa (prólogo) », El descontento y la promesa..., op. cit., p. 18

13. Como los Fondos Concursables del Ministerio de Cultura, que se suma a otros mecenazgos importantes, el Premio Nacional de Narrativa convocado por la Editorial Banda Oriental o las diferentes convocatorias de la Intendencia Municipal de Montevideo, entre otros.

14. Es reseñable destacar que HUM es la única editorial uruguaya que distribuye sus títulos de narrativa simultáneamente en Argentina.

15. Precisamente el mismo título de la columna que Mario Levrero escribió para la revista Postdata y que publicaría en Cauce en 2001.

16. Por edad, Mella pertenecería a la generación última, que Achugar cierra en torno a 1973, o de los nacidos después del comienzo de la dictadura. Sin embargo sus novelas aparecen a finales de los noventa. Mella puede decirse que sea el más prometedor narrador de su generación. A los veintiuno recibe ya el reconocimiento de El País Cultural al libro del año por su novela Derretimiento (1998), la narración de los crímenes de un psyco-killer uruguayo, que recuerda a ciertos personajes de Joyce Carol Oates. En 1999 aparece un relato suyo en la antología compilada por Eduardo Becerra, Líneas aéreas, para Lengua de trapo. El indiscutible talento de Mella se quedó estancado en su tercera novela. Hasta la fecha publicó Pogo (1997), Derretimiento (1998) y Noviembre (2000), recientemente reeditados por HUM.

17. Polleri es autor de alguno de los textos más originales de la narrativa uruguaya reciente, con frecuencia novelas de artista, narradas por un yo que puede reconocerse en cada una pese a la diversidad de personajes. Entre sus obras cabe mencionar El alma del mundo (2005), Gran ensayo sobre Baudelaire (2007), La inocencia (2008), El pincel y el cuchillo (2011) y la reedición, en Hum, de sus primeras obras, Carnaval (1990), Colores (1998) y El rey de las cucarachas (2001), ahora como trilogía bajo el título de El dios negro (2010).

18. Así lo sugiero en mi ensayo Realismos del simulacro: imagen, medios y tecnología en el Río de la Plata, (tesis doctoral), Editorial de la Universidad de Granada, 2008. http:// 
hdl.handle.net/10481/2067. Coinciden en esta observación los antólogos Achugar, op.cit.y Bernardo, op.cit.

19. J. Montoya Juárez, «Aira y los airianos: literatura argentina y cultura masiva desde los noventa ", J. Montoya y Á. Esteban (eds.), Entre lo local y lo global : la narrativa latinoamericana en el cambio de siglo (1990-2006), Madrid, Iberoamericana, 2008, p. 51-75.

20. G. Lagos, « Nuevas generaciones de narradores uruguayos », Revista Todavía, no 22, diciembre de 2009. http://www.revistatodavia.com.ar/todavia25/22.literaturanota.html.

21. Este último, el más exitoso del grupo, despliega una estética camp-queer, en la senda de la literatura de Puig. Escribe y se mueve a ambos lados del Río de la Plata. De hecho sus libros aparecen antes en Argentina que en Uruguay. La literatura en el caso de Umpi, y de alguno de los otros, no se desvincula de la construcción de una suerte de personaje público, en su caso es músico, cantante y performance. Una rara avis en Uruguay que empieza a serlo menos. El despliegue de actividades artísticas simultáneas es una marca de la última generación de narradores en Uruguay (Achugar, 2008). Ramiro Sanchiz también se dedica a la música. Por su parte Rodolfo Santullo, hermano de un popular músico, se dedica también al cómic y a la historieta.

22. I. Bajter, «El levrerismo : un movimiento a la zaga ", Brecha, artículo aparecido en 2007, cito del el texto de G. Lagos, op.cit.

23. G. Lagos, « Nuevas generaciones de narradores uruguayos », op.cit.

24. Precisamente el programa toma su nombre de un título de Levrero, La máquina de pensar en Gladys (1970).

25. Portland es una ficción deslocalizada, por cierto prologada por el mismo Levrero, donde, a partir de un argumento de inicio policial, una investigación azarosa del protagonista acerca de por qué el nombre de su novia aparece en un diskette encontrado en la calle, una mirada descolocada recorre diversos no lugares del presente, deviniendo en una reflexión sobre la decadencia, el deterioro físico y la madurez.

26. Quizás sea de este grupo Fernanda Trías, la autora que ha tenido una proyección más internacional, con su celebrada La azotea, excelente novela que narra el desplome de una familia tras la muerte de la madre, momento en el cual la hija comienza una enfermiza relación incestuosa con su padre, en una atmósfera claustrofóbica. Narrada en primera persona, la novela le huye a lo folletinesco y bucea en el procesado psicológico de la realidad a cargo de la voz adolescente.

27. En R. Sanchiz, «En busca del mapa difuso-lectura de narrativa uruguaya reciente », Esquina Corrientes, Revue transfrontalière de chroniques portègnes, 16 de junio 2011, http:// esquinacorrientes.wordpress.com/2011/06/16/en-busca-del-mapa-difuso-lectura-de-lanarrativa-uruguaya-reciente/.

28. Cabe citar la importancia que cobra el Semanario La Diaria, donde trabajan Lagos y Sanchiz, y en el que colaboran muchos de estos jóvenes. Su irrupción en los últimos años proporciona una presencia mediática clave para esta generación.

29. G. Lagos, op. cit.

30. El término «serios », personalmente, no me parece el más afortunado, en la medida en que, por ejemplo, alguna de las ficciones más « serias » o mejor formalmente construidas de la década pertenecería al grupo que Lagos llama «intimistas », como ocurre con La azotea o con Portland. Subrepticiamente se desliza un posicionamiento que toma partido por los últimos sobre los primeros. Sí es cierto que la aproximación que hace Lagos es valiosa y resulta útil -a mí, lector extranjero, me lo resulta- para comenzar a leer. Creo que, por el contrario, la vocación culturalista de estos autores podría ser antes el rasgo que los reuniera, la densidad de sus referencias culturales, frente al experimentalismo con el punto de vista, mucho más central en las propuestas de los anteriores.

31. R. Sanchiz, « En busca del mapa difuso », op.cit. 
32. Por otro lado, Sanchiz también reconoce el magisterio oblicuo de Levrero. Su volumen de cuentos Algunos de los otros (2008) principia con un paratexto que cita de Levrero, una influencia clara de Levrero se puede leer en «El cuento vaciado », incluido en la antología que prologa Achugar, y en la novela La vista desde el puente, aparece el homenaje más literal, Jorge Varlotta se convierte en un personaje, aquí un detective y parapsicólogo, sus dos vocaciones divergentes. Quizás de una manera más central que en el primer Levrero (pensemos en Gelatina (1968)), en Sanchiz la ciencia ficción es el telón de fondo. Sin duda Levrero ha tenido que ver en el gusto por la fantasía y la ciencia ficción en la narrativa de nuevo cuño.

33. Otra cuestión interesante es que en la operación crítica de Lagos, la más útil pienso de las que he leído, se tiende a defender a este grupo de "serios ", con la particularidad de que todos son hombres. Aunque no he tenido la oportunidad de consultarla antes de terminar el artículo, ha aparecido recientemente una antología titulada 22 mujeres (2012), a cargo de Alicia Torres ; en un prólogo combativo defiende las líneas disímiles que representan las autoras elegidas, todas del nuevo siglo, algunas ya consolidadas, como Sofi Richero, Fernanda Trías, Natalia Mardero, Laura Chalar o Mercedes Estramil. Pero muchas de ellas nuevas. Sin duda una nómina importante que debería tenerse en cuenta para dibujar el panorama de la última narrativa uruguaya.

34. Ver J. Rial, De mitos, memorias y políticas : la represión, el miedo y después, Montevideo, Ediciones de la Banda Oriental, 1986.

35. Algunos sociólogos vinculan la crisis del imaginario a la consolidación en Uruguay de un habitus migratorio, que arranca de la experiencia previa de la dictadura y se reactiva en los nuevos flujos que habían elevado la tasa migratoria al exterior durante los dos mil al $16 \%$, una de las más altas de América Latina. A este respecto véase el trabajo de A. Pellegrino (Migración de mano de obra calificada desde Argentina y Uruguay. Programa de migraciones internacionales. Genève, OIT, 2003) o el de N. Moraes Mena, op. cit.

36. H. Achugar, «Uruguay: el tamaño de la utopía», H. Achugar et al. (comps.), Identidad uruguaya : mito, crisis o afirmación, Montevideo, Trilce, 1992, p. 75-96.

37. Sobre esta cuestión véase J. Montoya y N. Moraes, «El último que apague la luz : emigración y crisis de identidad en la narrativa, el cine y la música uruguayos ", Revista Nuestra América ํㅡ 6, agosto-diciembre 2008, Universidad de Oporto, p. 205-233.

38. Dos vectores de la literatura globalizada, en opinión de Aínsa, en «Palabras nómadas », op.cit.

39. Un guiño a Derretimiento, de Mella. La temática de la novela de Stahl es también la historia de un asesino en serie.

40. R. Sanchiz, La vista desde el puente, op.cit., p. 9.

41. G. Lagos, "Tres antiartiguistas", en el blog Enormes lagos, http:// enormeslagos.blogspot.com.es/2011/12/tres-antiartiguistas.html2011. Reseña de la reedición del volumen historiográfico de Guillermo Vázquez Franco (Francisco Berra: la historia prohibida), del estudio El padre nuestro Artigas, de Fernando Andatch y el fotógrafo Martín Atme, y de la novela de Sanchiz.

42. El Bicentenario, oportunismo criticado por algunos reseñistas. Ver Á. Buela, «El código Artigas ", El País Cultural, http://www.elpais.com.uy/suplemento/cultural/el-codigo-artigas/ cultural_620364_120127.html.

43. N. Moraes Mena, Transnacionalismo político y nación..., op.cit, p. 758.

44. Idem, p. 758.

45. R. Williams, Marxism and Literature, Oxford U.P., 1977, p. 122-123.

46. C. Martínez Sarasola, «Pueblos originarios, procesos de reetnización y cuestiones identitarias : El caso de la comunidad günün a küna-mapuche Vicente Catrunao Pincén en las Pampas argentinas ", Diversidad, n 4, año 2, junio 2012, p. 57-81.

47. Vid. Moraes Mena, Transnacionalismo..., op.cit.

48. R. Sanchiz, La vista..., op.cit., p. 54.

49. Idem, p. 39. 
50. Idem, p. 10.

51. Idem, p. 11-12.

52. La retórica fantacientífica es patente en numerosas descripciones de algunos escenarios urbanos, o en la reiterada referencia a mundos posibles a partir de puntos de jonbar de la historia, desde ese universo paralelo a otros mundos, incluido el nuestro. La novela ensaya la relectura de temas borgesianos a partir de mediaciones subculturales del género.

53. Idem, p. 11.

54. Idem, p. 54.

55. Idem, p. 11.

56. Idem, p. 33.

57. E. Azcuy Ameghino, Artigas y los indios, Montevideo, Ediciones Andresito, 1991, p. 23.

58. Ver W. Mignolo, Historias locales/diseños globales, Madrid, Akal, 2003, p. 27-28.

59. R. Sanchiz, La vista, op.cit., p. 109.

60. Idem, p. 109.

61. Idem, p. 109.

62. Idem, p. 108.

63. Idem, p. 152.

64. Idem, p. 109.

65. Fruto de ese fenómeno son los esfuerzos por obtener la visibilización de las minorías articulados «desde abajo» (como los recogidos por Arocena y Aguiar, Multiculturalismo en Uruguay: ensayo y entrevistas a once comunidades culturales, Montevideo, Ediciones Trilce, 2007), pero también desde arriba, como la aprobación de ciertas leyes, como la ley contra el racismo, de 2004, o la Ley en la que se decreta el 3 de diciembre como Día Nacional del Candombe, de 2006.

66. Tras el punto de derrisión que marca el final de la conferencia en la novela, punto de saturación del Proyecto moderno que en la novela se identifica con la construcción de la narrativa identitaria nacional uruguaya fundada en una mitología ficticia, la novela tematiza una cierta apertura a la utopía como un « bricolaje existencial » (Maffesoli, La contemplation du monde. Figures du style communautaire, París, Grasset, p. 141) realizable apenas en la vida cotidiana, una " microutopía de la vida cotidiana », como llama Francisca Noguerol a las utopías que ve emerger en la literatura latinoamericana reciente (en «Utopías intersticiales: la batalla contra el desencanto en la última narrativa latinoamericana", F.Noguerol, M.A.Pérez, A.Esteban y J.Montoya (eds.), Literatura más allá de la nación..., op.cit., p. 61-75).

\section{RESÚMENES}

La multiterritorialidad caracteriza las identidades sujetas a diferentes procesos de transnacionalización cultural en nuestro presente. Una parte significativa de la ficción contemporánea, particularmente en Uruguay, apunta antes que a una desterritorialización a una multiterritorialidad, sea ésta fruto de una experiencia real de deslocalización transnacional o sea una multiterritorialidad imaginada. A esta última responde en particular la novela de Ramiro Sanchiz, La vista desde el puente (2011). Este artículo muestra cómo la ucronía de Sanchiz invierte la visualización del Uruguay como una porción desgajada de la Argentina que late en las referencias a Uruguay como « la Banda Oriental » y cuestiona los límites del territorio uruguayo a la vez que se ponen en crisis las narrativas identitarias en torno a las cuales se había venido 
construyendo la identidad nacional del Uruguay. A partir del análisis de su obra, se reflexiona acerca de algunas características de la ficción uruguaya reciente y se plantea finalmente un corpus para un estudio ulterior en curso que analizará las diferentes formulaciones de esta multiterritorialidad en la literatura uruguaya del presente siglo.

La multi territorialité caractérise les identités qui s'attachent à des différents processus de la transnationalisation dans l'actualité. Une partie significative de la fiction contemporaine, en particulier en Uruguay, vise plus qu'à une transnationalisation, à une multi territorialité, tirée soit d'une expérience de la réalité de délocalisation transnationale, soit d'une multi territorialité imaginée. C'est à cette dernière que répond particulièrement le roman de Ramiro Sanchiz, $L a$ vista desde el puente (2011). Cet article montre comment l'«uchronie» de Sanchiz, renverse la visualisation de l'Uruguay en tant que territoire détaché de l'Argentine; l'Uruguay évoqué comme « la Banda Oriental » questionne ainsi les frontières de ce territoire en même temps que les narrations d'identité autour desquelles s'est construite l'identité nationale de l'Uruguay. À partir de l'analyse de son œuvre, nous allons mener une réflexion à propos de quelques caractéristiques de la fiction uruguayenne actuelle. Il s'agira à terme de poser un corpus pour une étude ultérieure qui analysera les différentes formulations de cette multi territorialité dans la littérature uruguayenne du XXIème siècle.

This article examines a set of sixty seven letters that Uruguayan narrator Juan Carlos Onetti sent, from Montevideo to Buenos Aires, to Argentinean critic and art historian Julio E. Payró during the 1937-1955 period. This analysis focuses on a series of topics and questions of utmost significance in terms of « onettian » fiction. This approach synthesizes various relevant themes: the culture of his time, the analyses of the cinema of the moment, remarks on the books he reads and, most importantly, his reflections upon painting and his constant reference to literature as having a key role in his aesthetic reflections. Additionally, this analysis incorporates the significant figure of Constructivist painter Joaquín Torres García to the already existing extensive cultural exchange between the two shores of the Rio de la Plata.

\section{ÍNDICE}

Palabras claves: narrativa uruguaya del siglo XXI, multiterritorialidad, transnacionalismo, globalización, imaginarios identitarios, ucronía

Mots-clés: production narrative uruguayenne du XXIème siècle, multi territorialité, transnationalisation, globalisation, imaginaires identitaires, uchronie, Ramiro Sanchiz

Keywords: Uruguayan fiction from the XXIst century, multiterritoriality, transnationalism, globalization, identity imageries, ucrony

\section{AUTOR}

\section{JESÚS MONTOYA JUÁREZ}

Universidad de Murcia 